\section{“VOYAGE THROUGH COVID" A DESCRIPTIVE INSTITUTIONAL STUDY}

KEY WORDS: covid19,pandemic,lockdown, healthcare.
Dr

Shanthimalar $\mathbf{R}$

Dr Muthuchitra S

Dr

Semmanaselvan K Tamilnadu, India.

\section{Dr Indu S P*}

Dean, Government Kilpauk medical college, Chennai, Tamilnadu, India Dean, Government Kilpauk medical college, Chennai,Tamilnadu, India.

Head of the department of ENT, Government Kilpauk medical college, Chennai,Tamilnadu, India.

Associate professor in ENT, Government Royapettah Hospital, Chennai, Resident, Department of Otorhinolaryngology, Government Kilpauk medical college, Chennai, Tamilnadu, India. *Corresponding Author

달

Our Indian healthcare system is unique and has faced a lot of challenges in different point of times. One such challenge is tackling through this covid-19 pandemic.WHO declared the novel coronavirus outbreak a pandemic on march 11,2020 . The Indian government announced lockdown on 23rd march 2020 with social distancing and self isolation norms which is continued till now with certain relaxations and limitations.Both the pandemic and Lockdown has created an equally significant impact in the lives of every individual especially in the lives of the frontline healthcare workers. It has been a tedious job for both the government and the doctors in spreading awareness to the public regarding the pandemic. Each institution had had different methods of execution of their duties in order to overcome the pandemic. This article is to share my experience through this covid pandemic from our institution point of view.

\section{INTRODUCTION :}

This article is to share our institutional experiences during the covid pandemic, and the various challenges faced throughout this pandemic and on the various activities and steps in order to get control of the pandemic.

\section{The Ignition:}

Our journey starts from march 2020 into a preliminary meeting. To achieve great things, planning and enough time are the two preliminary requisites. The meeting was held to discuss about organizing teams, infrastructure, equipments and essential lab services to deal with the pandemic situation.

We were asked to volunteer for the teams for the administrative work, testing, reporting and for the laboratory services where there were no volunteers to march out initially. And then the teams were formed by the direction of Dean, the Vice principal, the Medical superintendent of our institution.

\section{Teamwork-Towards The Dreamwork:}

The overall control rests with the administration team ; consisted of five members the Dean, the Vice principal, the Medical superintendent, myself and Dr.Thirunavukarasu_ HOD, PMR.

- The test team is headed by Department of Medicine.

- The Reporting team is headed by the vice principal

- The Department of community medicine.

- The Lab department by Microbiology department.

- The Peripheral Care Centers, Food, Accommodation/ HR work by the Administration team.

- Death/mortuary headed by Forensic Department.

\section{The Progression:}

Days passed and around May, June, July the number of corona patients were at the peak. To add on, with the very less number of health personnels.In the beginning , the attitude of the health personnel were 'Why me ?'We had to train in ourselves that we are frontline workers like warriors during a war.This further led to involvement by all the healthcare workers and there were many sleepless nights and work without break for almost 90 days.Those personnel were accommodated and provided food by the admin team through the government.also the patients admitted in covid wards were also provided with special diet adequately making it easier for isolation.

We planned our Donning/Doffing Isolation areas meticulously to avoid cross infection. And made PPE available in adequate quantity.To avoid suffocating the hospital and in order to reduce the workload, the asymptomatic/mild symptomatic patients were isolated and monitored in CCC's (Covid Care Centres) manned by health personnels from our institute. We had 10 centres attached along with 2 screening centres.

Treatment team had a lot of recommendations given and withdrawn. So our institute had their own protocol.

\section{Challenges:}

Doctors and healthcare workers who are responding to a global health crisis and trying to protect individuals, families and communities in adverse situations with the same infrastructure, manpower and equipment to cater almost double the patient strength. This had led the doctors to work with stretched resources, shortage of personal protective equipment (PPE) and other equipment's, hence the morale of the team to be updated in order to cope up for the shortage.

Risk of cross infection both for the patients and also the healthcare workers has been becoming an increasing problem.Doctors, for instance, may have a duty to care for patients as well as a duty to care for their own families by protecting them (and hence themselves) from infection. ${ }^{[4]}$

Corona Care centres were started by our government in order to combat the burden of the patient load tertiary hospitals,so that mild asymptomatic cases could be monitored and treated by home isolation. The covid care centres, their duty allotment and functioning were maintained by our admin team.

Patient's attitude to isolation-With The sudden evolution with the pandemic and with the gearing up of cases towards peak, This has made people fearful, anxious, and sometimes they have found it difficult to access emergency treatment. The lockdown has exacerbated the problem, with patients unable to access healthcare due to transport suspension, fear of law 
enforcement and frustration following quarantine or containment zone restrictions

Due to fear and to avoid the risk of spreading the novel coronavirus SARS-CoV-2 infection, many hospitals have closed their doors to patients who have been trying to avail these facilities. This has led to restlessness, irritation and sometimes despair among the patients when trying to find medical help, And patient's adjustment to the available facilities was worrisome.

This created a dilemma.As the pandemic condition is a novel condition, there were no previously formulated guidelines fot the management of the condition. The different treatment options suggested worldwide and the new guidelines framed then and there creaed a dilemma among the treating doctors too.

As the number of cases have been raising tremendously and unexpectedly, there were massive reports to be delivered and reported. This has largely influenced the workload of doctors who had to work Day and Night.

Death rate was increasing and there were many number of deaths especially in the adults and elderly which led to emotional downfall in the whole nation. In children, at least in this wave of the pandemic and hopefully in the future, COVID19 is a comparatively rare cause of death ${ }^{[5]}$.

Gradually the disease was getting under control in certin areas where the awareness among people was high and considered . whereas in remote places where people had less knowledge on the pandemic,the case load was reaching a hike. And the policymakers and government had a big responsibility of recruiting the manpower from lesser affected areas to the most needed places. This distant working of the doctors away from their own workplace and families has created a mindstorm among many. This change in the face of lockdown added to the issue.

Inspite of the covid cases, the hospitals had to run the normal cases too which were also equally increasing gradually. When many other hospitals have closed their ways during the pandemic,people had to come to the government hospitals which were already dealing much with the pandemic cases. Inspite of the load due to pandemic, the government hospitals had to take care of the other non covid emergencies and the non emergencies too thus bringing the manpower to a much lower count. The workload was nerve breaking for the health personal.

Most patients were unwilling for isolation; felt they were imprisoned. Counselling was given when and where necessary.Patients complained about the food/facilities provided by the government. We conveyed them with the issues faced to provide facilities.

Reporting formats were numerous and frequent; almost daily reports. Adequate team work was done $24 * 7$.

When an infected patient dies, the body handling was an issue and we had a team of 5 members only for that part.

\section{CONCLUSION}

In the wake of pandemic , amidst the unexpected surge, right where the resources were inadequate right to till where we are almost nearing the control on the pandemic,there had been much struggles and changes in the healthcare system. This was almost possible by the inadvertent work by all the healthcare personnels and the load of help provided from the government regarding the needs of the doctors and the patients. Being the professor of ENT,where we had to deal totally with the airway and aerosols which poses high exposure and risk, we had a hell of experience sharing the work during pandemic control,Inspite of handling the regular non covid cases and also dealing with the emergency procedures. This pandemic has not only has had impact with working but has also affected the daily clinical observation of the medical students,both undergraduates and postgraduates. It took a great courage and a real challenge to face and to tide through the pandemic.

\section{REFERENCES}

1. Johnson SB, Butcher F.J Med Ethics 2021;47:12-15. Doctors during the COVID19 pandemic: what are their duties and what is owed to them?

2. Iyengar KP, Jain VK, Vaishya R. Postgrad Med J 2020;0:1-2. Current situation with doctors and healthcare workers during COVID-19 pandemic in India.

3. Malm H, May T, Francis LP, et al. Ethics, pandemics, and the duty to treat. Am J Bioeth 2008;8(8):4-19

4. Sokol DK. Virulent epidemics and scope of healthcare workers' duty of care. Emerg Infect Dis 2006;12(8): 1238-41.

5. Bhopal S, Bagaria J, Bhopal R. Children's mortality from COVID-19 compared with all-deaths and other relevant causes of death: epidemiological information for decision-making by parents, teachers, clinicians and policymakers. Public Health. 2020;185:19-20. doi:10.1016/ j.puhe. 2020. 05. 047 